\title{
FIRST DESCRIPTION AND MORPHOLOGY OF HAEMAL NODES IN PIGLETS (SUS SCROFA DOMESTICA)
}

\author{
Y. AKAYDIN $^{1 *}$ and M. KABAK ${ }^{2}$ \\ ${ }^{1}$ Department of Histology and Embryology, Faculty of Veterinary Medicine, \\ University of Mustafa Kemal, 31040 Antakya/Hatay, Turkey; \\ ${ }^{2}$ Department of Anatomy, Faculty of Veterinary Medicine, \\ University of Ondokuz Mayıs, Samsun, Turkey
}

(Received 30 May 2005; accepted 20 October 2005)

In this study, the presence of haemal nodes, previously recognised especially in ruminants, was determined for the first time in piglets. The morphology of haemal nodes located in the abdominal cavity of seven piglets was studied by gross inspection and by histological methods. Haemal nodes reddish in colour and oval or round in shape were observed on the thin branches originating from the caudal and cranial mesenteric arteries. These nodes, having connection only with blood vessels, were covered with a thin connective tissue capsule. The haemal nodes had a hilus at the entrance of which large blood vessels were seen. These blood vessels extended into the inside of the nodes through trabeculae. Afferent and efferent lymph vessels were not observed in the haemal nodes. The nodes contained many sinuses formed by reticular fibres and reticular cells and filled by red blood cells. In the haemal nodes, lymphocytic infiltration was more commonly seen than lymph follicles.

Key words: Haemal node, morphology, piglets

Haemal nodes are organs having connection with the blood circulation (Ezeasor and Singh, 1990; Cerutti et al., 1998). It has been stated that haemal nodes, which usually exist especially in ruminants and rats, are also present in horses and primates (Turner, 1969; Bacha and Wood, 1990; Raviola, 1994). Haemal nodes, which have structural and functional similarities with both the spleen and the lymph nodes, have functions related to the storage and filtration of blood, formation of thrombocytes,

*Corresponding author: Dr. Yesim Akaydin, PhD; E-mail: yakaydin@mku.edu.tr; Fax: 0090 (326) 245-5704 
and defence of the body (Ezeasor et al., 1989; Bacha and Wood, 1990; Raviola, 1994). The colour of haemal nodes, which are lined along the blood vessels, varies between brown and dark red (Getty, 1975; Dellmann and Eurell, 1998). The haemal nodes are located along the vertebral column, near the lymph nodes, and especially around blood vessels in the mediastinum, abdominal cavity, mesentery, pelvic cavity, and in regions under the skin (Getty, 1975; Gargiulo et al., 1987; Bacha and Wood, 1990; Thorp et al., 1991; Raviola, 1994).

The morphology, histochemistry and immunohistochemistry of haemal nodes have been extensively studied in ruminants (Singh, 1959; Ceccarelli et al., 1986; Gargiulo et al., 1987; Ezeasor and Singh, 1990; Thorp et al., 1991; Cerutti et al., 1998). The haemal nodes of ruminants do not comprise afferent and efferent lymph vessels. Furthermore, the cortex and the medulla cannot be differentiated and sinuses are filled with red blood cells in the haemal nodes (Singh, 1959; Getty, 1975; Gargiulo et al., 1987; Constantinescu et al., 1988). In pigs, there are structures that represent an intermediate between lymph node and haemal node. These structures, called haemolymph nodes, include blood and lymphatic vessels (Getty, 1975; Leeson et al., 1985). However, until the present study there was no information about the presence of haemal nodes in pigs. The objective of this work was to determine whether haemal nodes were present in piglets.

\section{Materials and methods}

Seven piglets (Sus scrofa domestica) were used in the present study. These piglets, aged between newborn and 60 days old, died immediately or at different intervals after birth because the sow did not feed them. The abdominal cavity of the piglets was opened immediately after death. The nodes, which were observed to be reddish in colour in five piglets, were dissected and fixed in $10 \%$ neutral buffered formalin solution for $24 \mathrm{~h}$. In two piglets, a cannula was placed from the aortic arch in order to better observe the capsule of the haemal node, and the tissues in the abdominal cavity were washed with $0.9 \% \mathrm{NaCl}$ solution. After the washing process, $10 \%$ neutral buffered formalin solution was injected with the same cannula. The nodes were fixed in $10 \%$ neutral buffered formalin solution for $24 \mathrm{~h}$. Then the nodes were excised, dehydrated and embedded in paraffin. Serial $5 \mu \mathrm{m}$ thick sections were cut from each paraffin block. Crossman's modified triple staining method was applied to study the general structure of the nodes (Denk et al., 1989). On several sections reticular cells and reticular fibres were visualised by Gordon and Sweet's silver technique (Bancroft and Cook, 1984; Kiernan, 1990). The blood cells were revealed by Giemsa technique (Bancroft and Cook, 1984). For the demonstration of plasma and mast cells, the methyl green-pyronin method (Bancroft and Cook, 1984) and toluidine blue stain (Kiernan, 1990) was used, respectively. 


\section{Results}

The haemal nodes of piglets were reddish in colour and their size varied between a pinhead and a pea. There were differences between the piglets in the location and number of oval or round nodes. The number of haemal nodes in the abdominal cavity varied between 5 and 15 .

The haemal nodes (Fig. 1A) were usually located between the lymph nodes lined in the mesocolon along the course of the left colic artery which was the branch of the caudal mesenteric artery, and between the lymph nodes located in the mesojejenum along the course of the jejunal artery originating from the cranial mesenteric artery. Haemal nodes were rarely seen along the course of the cranial rectal artery arising from the caudal mesenteric artery. A pea-sized haemal node was found among the abdominal aorta, ureter, caudal vena cava and the caudal end of the right kidney. In one piglet, a haemal node was located in between the cranial end of right kidney and the wall of the abdominal cavity. In another piglet, the node was seen at the ventral end of the adrenal gland.

It was observed that the haemal nodes, in which the cortex and the medulla could not be differentiated, had a connection with the blood vessels. Each node was covered with a thin capsule of connective tissue (Fig. 1B). The capsule contained capillary blood vessels, smooth muscle cells, fibroblasts, reticular fibres, reticular cells and occasionally mast cells (Figs 1B and 1C). Moreover, there were trabeculae leaning towards the inner part of the organ from the capsule (Fig. 1B). These trabeculae, comprising smooth muscle cells, reticular cells and reticular fibres, were more developed in the centre of the haemal nodes (Figs 1D and 1F). The haemal nodes also had a hilus containing blood vessels (Fig. 1B). These vessels extended into the inner part of the nodes from the hilus via the trabeculae (Fig. 1E). Typical afferent or efferent lymph vessels were not found in the haemal nodes. Lymphocytic infiltration was observed in the parenchyma of many haemal nodes (Fig. 1B). Some of the haemal nodes contained very few primary lymph follicles, but not in all parts of the nodes (Fig. 1E). In the regions associated with lymphoid tissues many lymphocytes and eosinophilic granulocytes were identified (Fig. 1G). Many sinuses formed by reticular fibres and reticular cells, and filled with red blood cells, were found in the haemal nodes (Fig. 1B). A few lymphocytes, eosinophilic and neutrophilic granulocytes were also present inside the sinuses (Fig. 1F). Plasma cells and mast cells were not found in the haemal nodes. 


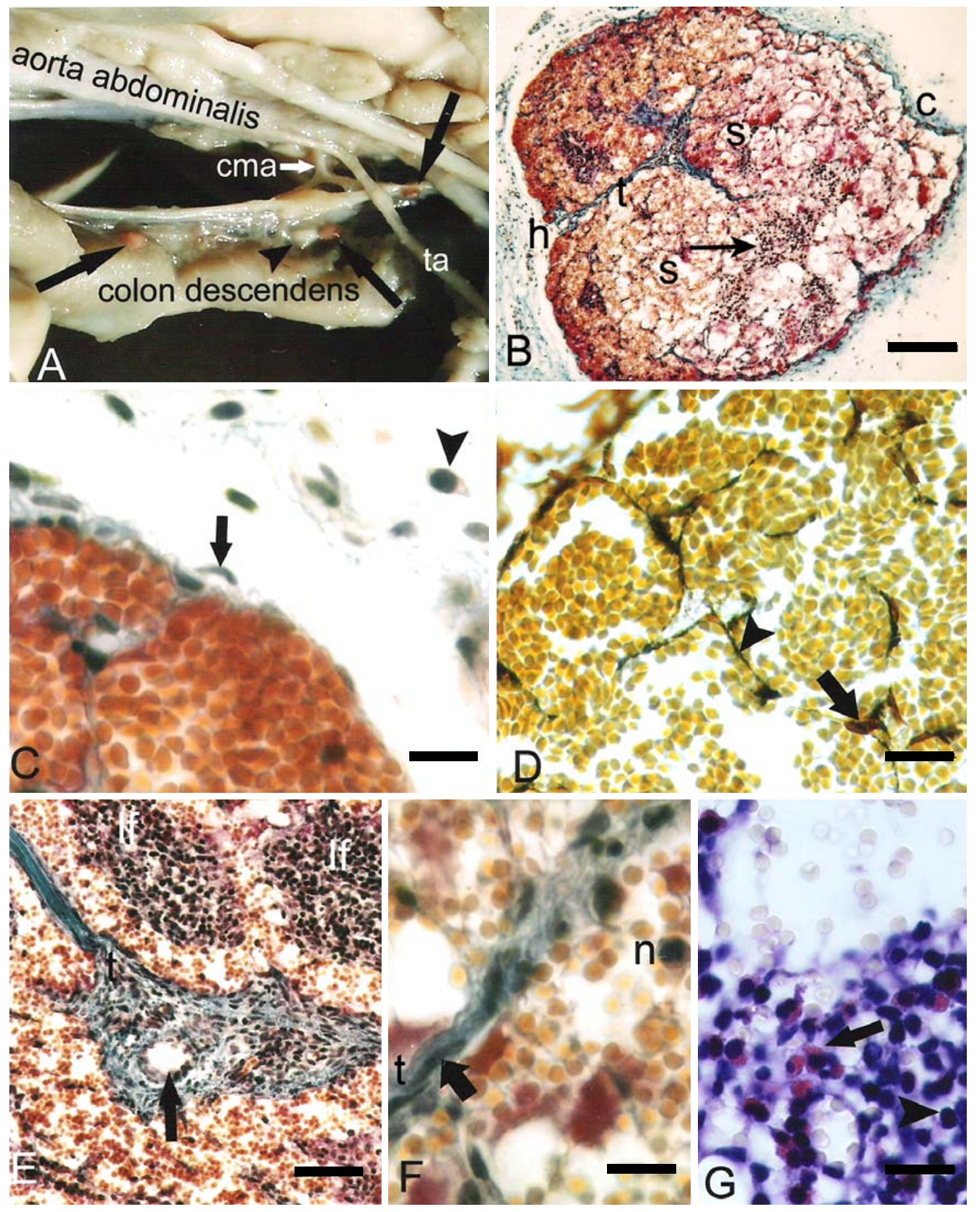




\section{Discussion}

Observations made during this study showed that the histological structure of haemal nodes in piglets was in some respects similar to that described in ruminants (Singh, 1959; Gargiulo et al., 1987; Ezeasor and Singh, 1990; Thorp et al., 1991; Raviola, 1994; Cerutti et al., 1998; Dellmann and Eurell, 1998). To the authors' knowledge this is the first report about the presence of haemal nodes in piglets.

The reason why haemal nodes were searched for in the abdominal cavity of the piglets is that especially in ruminants the haemal nodes were found to be located around the blood vessels and lymph nodes in the abdominal and thoracic cavities (Gargiulo et al., 1987; Bacha and Wood, 1990; Raviola, 1994). We found that the haemal nodes, which were close to the lymph nodes, were generally present along the branches of the cranial and caudal mesenteric arteries and sometimes between the abdominal aorta and the caudal vena cava. The location of haemal nodes in piglets was found to be similar to that reported for ruminants (Singh, 1959; Gargiulo et al., 1987; Bacha and Wood, 1990; Thorp et al., 1991; Raviola, 1994).

The haemal nodes have a connective tissue capsule and trabeculae dividing the inner part of the parenchyma and extending into the inside of the haemal node (Thorp et al., 1991; Cerutti et al., 1998). The capsule and the trabeculae of the nodes are supported by a small number of smooth muscle cells and reticular fibres (Gargiulo et al., 1987; Bacha and Wood, 1990). The capsule sometimes contains mast cells in the caprine species (Ezeasor and Singh, 1988). It is stated that there is a hilus in the organ where a large artery and a vein pass in and out (Gargiulo et al., 1987; Raviola, 1994). In piglets, the histological features of the capsule and the presence of a hilus were consistent with the findings of previous studies.

Fig. 1. (A) Macroscopic appearance of the haemal nodes in piglets. Haemal nodes (arrow) are seen between lymph nodes (arrowhead); cma: caudal mesenteric artery, ta: testicular artery. (B) Histological appearance of the haemal node; c: capsule, h: hilus, t: trabecula, s: sinus, arrow: lymphocyte infiltration. Triple stain, scale bar: $115 \mu \mathrm{m}$. (C) Fibroblast and smooth muscle cells are observed in the capsule. Arrow: smooth muscle cell, arrowhead: fibroblast. Triple stain, scale bar: $21 \mu \mathrm{m}$.

(D) Reticular cells and reticular fibres in the capsule and sinuses. Arrow: reticular cell, arrowhead: reticular fibre. Gordon and Sweet's silver staining method, scale bar: $30 \mu \mathrm{m}$. (E) Appearance of trabecula and lymph follicles in haemal nodes; lf: lymph follicle, t: trabecula, arrow: trabecular artery. Triple stain, scale bar: $40 \mu \mathrm{m}$. (F) Neutrophilic granulocyte in the sinuses; n: neutrophilic granulocyte, t: trabecula, arrow: smooth muscle cell. Triple stain, scale bar: $21 \mu \mathrm{m}$. (G) Appearance of the accumulation of lymphocytes. Arrow: eosinophilic granulocyte, arrowhead: lymphocyte; Giemsa staining method, scale bar: $28 \mu \mathrm{m}$ 
In the literature, there are differences associated with the presence of afferent and efferent lymph vessels in the haemal nodes. The lymph vessels are present in the haemal nodes of goats (Ezeasor and Singh, 1988, 1990) and camels (Zidan and Pabst, 2004) but not in those of sheep (Bacha and Wood, 1990; Thorp et al., 1991), buffalo calves (Singh, 1959) and oxen (Constantinescu et al., 1988). Our results showed that the haemal nodes of piglets had no lymph vessels, in the same way as in sheep, buffalo calves and oxen.

In the haemal nodes, the interstices of the reticular meshwork are filled with red blood cells (Constantinescu et al., 1988; Ezeasor and Singh, 1988; Dellmann and Eurell, 1998), and they contain many macrophages, plasma cells and lymphocytes (Gargiulo et al., 1987). Our findings are consistent with these reports, except for the presence of plasma cells and macrophages. It has been stated that the sinuses are absent in one-month-old goats and they are formed and increase in size as the age progresses (Ezeasor and Singh, 1988). A study conducted on the development of haemal nodes in cattle in connection with age found that the sinuses were first seen in embryos 38-39 cm in length but they were more clearly discernible in newborn calves (Windqvist, 1954). Our results were similar to those obtained in cattle but different from the findings reported for goats. Thorp et al. (1991) stated that the cortex and the medulla could be distinguished in the haemal nodes, whereas Singh (1959) and Getty (1975) reported that this differentiation could not be made without mentioning age. Moreover, Ezeasor and Singh (1988) also mentioned that differentiation of the cortex and the medulla was impossible in young animals only. In the present study, cortex and medulla could not be differentiated in the haemal nodes of piglets. The presence of primary and secondary lymph follicles in the cortex and cordon-like lymphatic tissue in the medulla of the haemal nodes has been reported (Ezeasor and Singh, 1988; Thorp et al., 1991; Cerutti et al., 1998). Dellmann and Eurell (1998) stated that there was lymphocytic infiltration in the haemal nodes of young animals, but the number of lymph follicles was lower as compared to that found in older animals. On the other hand, Windqvist (1954) reported that a small number of follicles were present in the peripheral parts of the node in newborn calves. In this study, lymphocytic infiltration was observed in the haemal nodes and primary lymph follicles were found at the centre of some haemal nodes. These results are similar to those reported by Dellmann and Eurell (1998).

Eosinophilic and neutrophilic granulocytes in the lymphoid tissues of bovine embryos and large numbers of eosinophils and mast cells in the adventitia of the arteries have been reported (Windqvist, 1954). In this study, eosinophilic and neutrophilic granulocytes were observed in the lymphoid tissue and within the sinuses. However, mast cells were not detected.

Getty (1975) mentioned that not all the nodes observed in dark red colour in pigs represent haemal nodes, because lymph nodes can also take a red appearance under conditions such as application of drugs in toxic doses, as well as after 
injuries and fatal operations connected with mechanical disorders. Such conditions did not exist in the piglets used in this study, which died immediately after birth or at different intervals thereafter because the sow did not feed them for an unknown reason. All the reddish nodes were collected from the abdominal cavity; however, some of them were not haemal nodes. In the nodes identified as haemal nodes, cortex and medulla were not distinguished, afferent and efferent lymph vessels were absent, and the sinuses were full of red blood cells. The histological appearance of haemal nodes was similar to that described in the literature.

In conclusion, the reddish haemal nodes of the piglets examined were seen adjacent to the lymph nodes, leaning through the branches of the cranial and caudal mesenteric arteries in the abdominal cavity. This is the first study describing the presence of haemal nodes in piglets and providing information on their anatomical features and histological structure, which is similar to that reported for the haemal nodes of ruminants.

\section{References}

Bacha, W. J. and Wood, L. N. (1990): Color Atlas of Veterinary Histology. Lea \& Febiger, Philadelphia. p. 66.

Bancroft, J. D. and Cook, H. C. (1984): Manual of Histological Techniques. Churchill Livingstone, London. pp. 49-50, 63-64, 83 .

Ceccarelli, P., Gargiulo, A. M., Fagioli, O. and Pedini, V. (1986): Cytochemical identification of lymphocytes and other mononuclear cells in ovine and bovine hemal nodes. Comp. Immun. Microbiol. Infect. Dis. 9, 297-302.

Cerutti, P., Marcaccini, A. and Guerrero, F. (1998): A scanning and immunohistochemical study in bovine haemal node. Anat. Histol. Embryol. 27, 387-392.

Constantinescu, G. M., Brown, E. M. and McClure, R. C. (1988): Accessory parotid lymph nodes and hemal nodes in the temporal fossa in three oxen. Cornell Vet. 78, 147-154.

Dellmann, H. D. and Eurell, J. (1998): Textbook of Veterinary Histology. 5th edition. Williams and Wilkins, Baltimore. pp. 146-147.

Denk, H., Künzele, H., Plenk, H., Rüschoff, J. and Sellner, W. (1989): Romeis Microscopische Technik. 17. Neubearbeitete Auflage. Urban und Schwarzenberg, München, pp. 439-450.

Ezeasor, D. N. and Singh, A. (1988): Histology of the caprine hemal node. Acta Anat. 133, 16-23.

Ezeasor, D. N. and Singh, A. (1990): Morphologic features of lymph vessels in caprine hemal nodes. Am. J. Vet. Res. 51, 1139-1143.

Ezeasor, D. N., Singh, A. and Sims, D. E. (1989): Erythrophagocytosis in caprine hemal node. Acta Anat. 134, 341-345.

Gargiulo, A. M., Ceccarelli, P. and Pedini, V. (1987): Architecture of sheep haemal nodes. Res. Vet. Sci. 42, 280-286.

Getty, R. (1975): The Anatomy of the Domestic Animals. 5th edition. W. B. Saunders Company, Philadelphia. p. 179.

Kiernan, J. A. (1990): Histological and Histochemical Methods. Second edition. Pergamon Press, New York. 92, 125-126.

Leeson, C. R., Leeson, T. S. and Paparo, A. A. (1985): Textbook of Histology. 5th edition. W. B. Saunders Company, Philadelphia. pp. 270-271.

Raviola, E. (1994): Lymph Nodes. In: Fawcett, D. W. (ed.) A Textbook of Histology. 12th edition. Chapman and Hall, New York. pp. 458-459. 
Singh, A. (1959): On the microscopic structure of haemal nodes of buffalo calves. Brit. Vet. J. 115, 271-275.

Thorp, B. H., Seneque, S., Staute, K. and Kimpton, W. G. (1991): Characterization and distribution of lymphocyte subsets in sheep hemal nodes. Dev. Comp. Immunol. 15, 393-400.

Turner, D. R. (1969): The vascular tree of haemal node in the rat. J. Anat. 104, 481-493.

Windqvist, G. (1954): The bovine hemal nodes. Acta Anat. 22, 108-112.

Zidan, M. and Pabst, R. (2004): Histological, histochemical and immunohistochemical study of the haemal nodes of the dromedary camel. Anat. Histol. Embryol. 33, 284-289. 